\title{
A Review of Structural Abnormality in Schizophrenia
}

\author{
Keran Xuan
}

\author{
Department of Psychology, University of Sydney, \\ Corresponding author.Email: kxua0627@uni.sydney.edu.au
}

\begin{abstract}
Over the past 20 years, the understanding of schizophrenia has deepened. As a brain disease, schizophrenia has profoundly affected generations. It is a chronic brain disorder that is characterized by significant alterations in perception, thoughts, mood, and behavior. Schizophrenia usually occurs in adults, especially young people. Therefore, it is extremely important to understand the cause of the disease. But the truth is that the cause of schizophrenia is very complex, until the last 20 years, the research community had the chance to deeply explore the structural abnormality of the brain in schizophrenia via function neuroimaging, especially Magnetic Resonance Imaging (MRI). These technological advances led to a better understanding of structural brain abnormalities in schizophrenia. This review presents findings from the last 20 years (2000-2021) in structural Magnetic Resonance Imaging (MRI). The result shows that the volume of gray matter decreased in schizophrenic patients. And the author finds that there seem to be no conclusive results in terms of white matter changes.
\end{abstract}

Keywords: brain structure abnormality, Magnetic Resonance Imaging (MRI), white matter, gray matter, schizophrenia

\section{INTRODUCTION}

Schizophrenia has been around for a long time, with the oldest description dating back to $1550 \mathrm{BC}$ in Egypt. But it wasn't until the 19th century that Emil Krapelin (1919) first used the term "Alzheimer" or "preterm dementia" to describe clinical confusion in patients, the first breakthrough in schizophrenia [1]. Bleuer (1950) then objected to Krapelin's definition of mental illness like dementia, and first used the term "schizophrenia" to distinguish between positive and negative symptoms [2]. The emergence of functional Neuron imaging such as brain scanning makes it possible to study brain structural abnormalities. In the following decades, as techiniques matured, interests in research flourished: In 1927, abnormalities in the interbrain structure between patients and non-patients have been found on a structural basis. In the 1920s and 30s, pneumoencephalogram studies were carried out based on brain imaging, and it was found that patients with schizophrenia had reduced brain volume and enlarged ventricles. Subsequent MRI scans also revealed multiple structural abnormalities in schizophrenia patients.

Among all these findings, gray matter change in the cerebrum is the most significant and widely researched. However, in studies of brain structural changes of people with schizophrenia, although the gray matter is one of the most widely studied targets, results have been mixed. For example, Luque et al. (2021) mentioned in his study that patients would show an accelerated decline in gray matter volume throughout the process of schizophrenia, while Tamnes et al. (2018) proposed that gray matter volume might increase in the early stage and gradually decrease in the later stage. Therefore, in these MRI tests, even though most literature believes that, in general, the gray matter volume decreases, no common conclusion can be drawn about the tendency of changes of gray matter volume through detection. Moreover, there are few generalizations and summaries of these studies. Therefore, this thesis aims to summarize a total of 28 pieces of literature by way of review, to analyze the overall changes in gray matter structure.

Further, researches on white matter are the least studied among all the abnormal structures. Only few literature mentioned the changes of WM, for instance, Zhang et al (2020) stated that the volume of WM decreased significantly. But Fusar-poil et al (2013) and Chow et al (2002) both claimed that there is no difference in WM volume between normal people and patients. From all these findings, the conclusion of how white matter changes is still controversial. Therefore, this thesis hopes to gain a consistent conclusion of how WM 
volume changes. On the basis of summarizing past studies, this thesis might also be summarized to provide ideas for subsequent studies by comparing different studies in different kinds of literature.

\section{METHODOLOGY}

This paper is based on the search in Scopus using the keywords "MRI" and "schizophrenia", and the time range is limited to 2000-2021. The reason is that the neuropathological search for schizophrenia has been so popular in the last 20 years that there has been enough literature on brain abnormalities. The results of literature retrieval were 3398 clicks. To better focus on brain structure, the author superimposes "brain structure" on the original restriction. In other words, the author aims to review structural changes in schizophrenia patients, rather than functional changes in other neurons or chemicals. The results showed 736 relevant articles. In order to better classify these results and clearly display the research results of different brain regions in recent years, the author conducted a more detailed retrieval of these works of literature. Among them, 103 literature related to white matter and gray matter changes (only 28 articles are closely related to the topic) as listed in APPENDIX I.

In a review of $28 \mathrm{MRI}$ studies, about $95 \%$ reported a reduction in gray matter volume, making it the strongest evidence for changes in gray matter volume. But one of the papers came to the exact opposite conclusion, suggesting an increase in gray matter volume [14]. In addition, although almost all literature agrees that, in general, gray matter volume decreases, there is disagreement about volume changes throughout the development of schizophrenia. Some studies indicate that the volume of GM had significant and accelerate reduction. However, a small number of other studies suggest that the volume of gray matter increases first and then decreases. In addition, in the studies of white matter volume, there is no consistent conclusion. Some literature suggests that white matter, like gray matter, gradually shrinks with the progression of the disease[4][25][27]. Others reported no difference of white matter abnormalities between normal and abnormal people.

\section{GREY MATTER ABNORMALITY IN SCHIZOPHRENIA}

\subsection{Introduction}

Over the past 20 years, brain imaging studies have shifted their research focus to schizophrenia, and a large number of brain structure maps and data have provided support for brain structural variation. Lawrie and Abukmeil (1998) suggested that schizophrenia and structural Coupling of Cerebrum [31]. One of the most important findings was the reduction of the Gray Matter Volume [32]. Other studies building on their work suggested that reduction of grey matter has been found in global [31], especially left superior temporal gyrus and insular cortex; left medial temporal lobe (including parahippocampal gyrus and hippocampus); significant loss of gray matter in the anterior cingulate gyrus and medial frontal gyrus [30]. Moreover, reduced gray matter can affect emotion, memory and visual systems [15].

But a careful review of these articles, it is easy to find though by comparing the healthy people and patients with schizophrenia of gray matter in brain volume change in the conclusion of each structure (around 95\%). In other words, changes in gray matter volume have been reported by most studies. However, there is little literature that mentioned the volume of white matter. The changes in white matter that occur as the disease progresses are not well understood. Different kinds of literature have different and sometimes contradictory statements about the alteration of white matter volume. Therefore, in the next section, the article will describe the views of four works of literature on white matter in detail, and hope to study the changes in white matter volume by comparing the results of different studies.

\subsection{White matter volume in schizophrenia}

Although MRI studies of structural abnormalities in white matter have provided little definitive information to date, a few studies have investigated large differences in[29] white matter volume between schizophrenics and the general population [33]. Several studies on the white matter have come to many different conclusions, in particular, chow et al (2002) compared tissue contrast and cortical thickness by MRI between schizophrenic patients and healthy people and showed no significant differences in total white matter volume between the two groups (as shown in figure 1). A line chart of white volume of healthy controls and patients. White points are data from healthy group, black points are from schizophrenia patients. The whole data shows weak correlation, which means there is no significant difference of white matter volume among them [29].
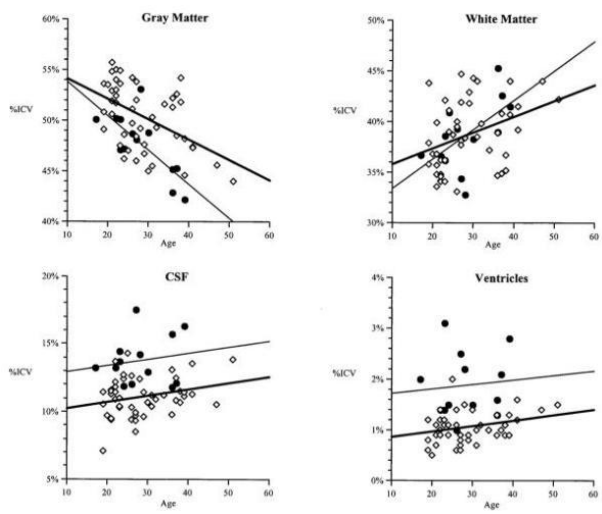

Figure 1 White matter volume of healthy controls vs schizophrenia patients 
However, Sigmundsson et al (2001) mentioned that there was a difference in white matter volume between healthy individuals and patients [30]. The total white matter volume was reduced in patients and there was white matter deficiency (as shown in figure 2). Meanwhile, Bopp (2017) noted an association between white matter reduction and decreased gray matter volume [13]. In addition, a study by Wible et al (1992) reported a decrease in white matter volume in the left frontoccipital fasciculus region, suggesting an association between structural changes in white matter and a decrease in frontal lobe volume as well [34]. Yellow area refers to the absence of white matter. Compare with healthy controls, schizophrenia patients have a significant loss in white matter volume [30].

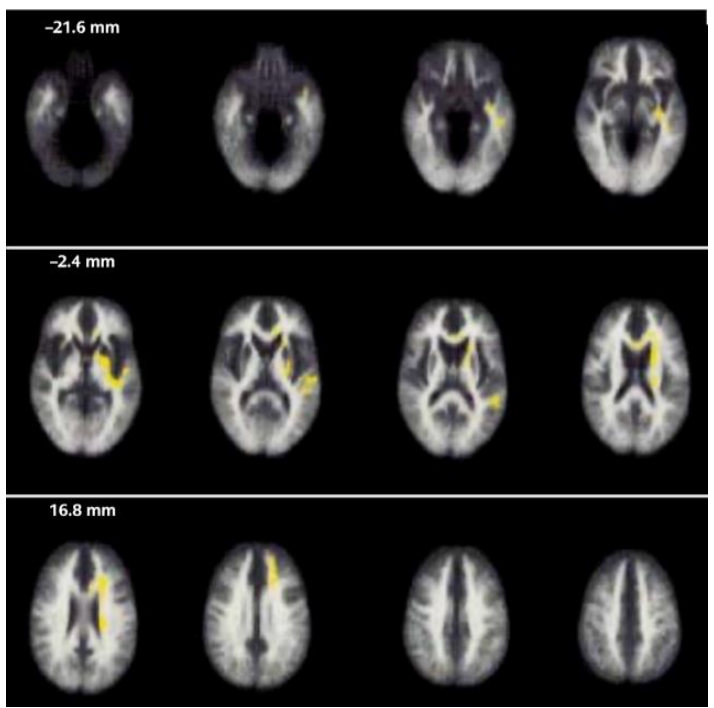

Figure 2 White matter volume differences between patients and healthy controls

\section{DISCUSSION}

In conclusion, the structure of white matter changes in schizophrenia remains controversial. Comparing normal people and patients, there is evidence that showed that there are some deficits in this aspect of white matter volumes in patients. However, there is also evidence, as yet unclear, that changes in white matter are associated with changes in other factors in brain structure, including gray matter, frontal lobes, etc. Although there are also experiments that did not find significant differences between healthy controls and patients, the various speculations and findings of white matter remain significant. Therefore, more work is needed to confirm these important findings, especially how white matter actually changes.

\section{CONCLUSION}

Over the past 20 years, a deeper understanding of the structural abnormalities of the brain caused by schizophrenia has been gained, thanks to the rapid development of neuroimaging techniques. Approximately 700 papers have explored structural changes in the brain on MRI, and these findings have shifted the focus of research to the neurobiology of schizophrenia. After reviewing about 30 of these papers that are closely related to changes in matter, the following findings were summarized: schizophrenic patients show an accelerated decline in gray matter and a decrease in volume, particularly in the frontal, temporal, and parietal cortices; at this stage, there is no conclusive evidence on how white matter volume changes, with some studies suggesting that patients have a white matter deficit and that it is related to a decrease in gray matter. Another part of the literature proposes that there is no significant difference in white matter.

Through the comparison of 28 pieces of literature, this thesis may provide ideas for subsequent researches and lead to a deeper understanding of the brain mechanism of schizophrenia. However, there is a certain limitation in this thesis. It only summarized the findings in the past ten years without conducting experiments with a scientific basis, which means its accuracy needs to be improved. Moreover, it cannot be used as substantive evidence of brain structure changes in schizophrenia.

Therefore, future research can be improved from the following two aspects. Firstly, the selection of the experimental population needs to be more careful. If different experiments tend to select the same or similar research objects, the conclusion obtained after MRI test will be more accurate (rather than drawing different conclusions using entirely different subjects, as in previous experiments). Secondly, MRI can only show changes in brain structure relatively statically, not dynamically, so better techniques are needed to detect changes in brain structure. However, with more research and technical refinement, after decades, a more complete understanding of the structural abnormalities of the brain in schizophrenia might be got.

\section{ACKNOWLEDGMENTS}

Firstly, I would like to express my sincere gratitude to everyone who helped me in the whole thesis process, including my teachers and professors, they provided me with valuable suggestions during every stage of the thesis. In the thesis topic selection, they affirmed my topic selection, at the same time they also gave me detailed guidance. Moreover, I would like to thank all my friends and especially my parents who encourage and support me when I lacked confidence. Further, I would like to show deep gratitude to the research support of Scopus and all the authors of the references that I cited. 
APPENDIX I Magnetic resonance imaging findings of white matter and grey matter in schizophrenia

\begin{tabular}{|c|c|c|}
\hline Reference & $\begin{array}{l}\text { Participants } \\
\text { (cases/healthy } \\
\text { controls) }\end{array}$ & MRI findings \\
\hline Luque et al., 2021 & $2473 / 990$ & The patients showed an accelerated decline in gray matter mainly in the temporal, frontal, cingulate and parietal cortex [3]. \\
\hline Stauffer et al., 2021 & $69369 / 236642$ & The genetic mechanism of schizophrenia may lead to cortical and white matter microstructure changes[4] \\
\hline Pijnenborg et al., 2020 & I & Low gray matter, white matter volume, and frontal gyrus gray matter volume were associated with poor insight [5]. \\
\hline Nazeri et al., 2020 & 1 & Autopsy studies have shown abnormalities in gray matter microstructure in patients with schizophrenia[6]. \\
\hline Zhang et al., 2020 & $117 / 86$ & The amount of gray and white matter in motor areas of the cerebral cortex decreased significantly [7] \\
\hline Drakesmith et al., 2019 & $21 / 15$ & There was a shift in the relationship between white matter structure and volume[8]. \\
\hline Wang et al., 2019 & I & $\begin{array}{l}\text { The increasing volume of gray matter in the dorsolateral and medial prefrontal cortex is related to the increase of integrity } \\
\text { of white matter fibers such as the conspiratorial tract[9]. }\end{array}$ \\
\hline Jirsaraie et al., 2018 & $247 / 206$ & When global cognitive deficits were present, executive function was significantly correlated with white matter[10]. \\
\hline Tamnes et al., 2018 & I & $\begin{array}{l}\text { Studies have shown that rapid growth in gray matter structure early in life is usually accompanied by a later decline, while } \\
\text { white matter continues to increase throughout childhood and adolescence[11]. }\end{array}$ \\
\hline Delvecchio et al., 2017 & $58 / 59$ & The volume of gray matter in the left temporal plane decreased in female schizophrenics $(F=4.58, P=0.03)[12]$. \\
\hline Bopp et al., 2017 & $26 / 26$ & $\begin{array}{l}\text { There were some changes in the structure of gray matter and white matter, and differences were found in } 9 \text { white matter } \\
\text { tracts among groups[13]. }\end{array}$ \\
\hline Riddle et al., 2017 & $833 / 600$ & $\begin{array}{l}\text { Brain structural abnormalities are subtle increases in total brain volume due to increased gray matter, but there is little } \\
\text { evidence of region-specific effects[14]. }\end{array}$ \\
\hline Lu et al., 2016 & $41 / 42$ & $\begin{array}{l}\text { SZ patients show GM and WM abnormalities in several brain structures primarily involved in the emotional, memory, and } \\
\text { visual systems[15]. }\end{array}$ \\
\hline Francx et al., 2016 & $129 / 204$ & $\begin{array}{l}\text { After analysing the independent component for gray matter volume, cortical thickness, surface area expansion, and white } \\
\text { matter diffusion index, the data indicated that participants with more symptoms had smaller prefrontal volume and } \\
\text { abnormal prefrontal white matter index[16]. }\end{array}$ \\
\hline Torres et al., 2016 & $23 / 23$ & $\begin{array}{l}\text { By small volume correction (SVC) analysis, patients with first-episode schizophrenia showed a small number of volume } \\
\text { deficits in a limited network of brain regions, and patients with chronic schizophrenia showed a broad regional GM volume } \\
\text { decrease compared to controls, including bilateral superior, inferior, orbitofrontal cortex, right middle frontal cortex, } \\
\text { bilateral anterior cingulate cortex, bilateral insula and right superior temporal lobe and middle temporal lobe. These } \\
\text { declines are related to age[17]. }\end{array}$ \\
\hline Hajek et al., 2015 & $36 / 45$ & $\begin{array}{l}\text { Application of } \\
\text { Machine learning to grey matter did not distinguish either the unaffected HR or affected familial groups from control } \\
\text { groups[18]. }\end{array}$ \\
\hline Nenadic et al., 2015 & $43 / 24$ & $\begin{array}{l}\text { First-episode SZ patients had reduced gray matter in regions of the left prefrontal lobe, insula, right parietal lobe, and left } \\
\text { temporal cortex, while those in the high-risk group had reduced gray matter in the right middle temporal cortex and left } \\
\text { prefrontal cortex[19]. }\end{array}$ \\
\hline Juola et al., 2014 & 54 & $\begin{array}{l}\text { After controlling for multiple covariates, increased density of the left limbic area was associated with fewer } \\
\text { hospitalizations and increased total white matter volume with being in remission. Higher density of left frontal grey matter } \\
\text { was associated with not being on a disability pension and higher density of the left frontal lobe and left the limbic area } \\
\text { were related to better functioning. Higher density of the left limbic area was associated with a better longitudinal course of } \\
\text { illness [20]. }\end{array}$ \\
\hline Liu et al., 2014 & $17 / 17$ & $\begin{array}{l}\text { Patients had smaller GM volumes and thinner temporal cortex. The anatomic correspondence between WM integrity } \\
\text { abnormalities and GM changes in schizophrenia shows that there is a difference between the two sexes[21]. }\end{array}$ \\
\hline Thermenos et al., 2013 & 1 & The accelerated reduction of gray matter volume over time is related to symptoms and cognitive deficits [22]. \\
\hline Fusar-poli et al., 2013 & $1046 / 780$ & $\begin{array}{l}\text { No baseline volume abnormalities were observed in gray and white matter volume, cerebrospinal fluid, and caudate } \\
\text { nucleus [23]. }\end{array}$ \\
\hline Kong et al., 2012 & 1 & $\begin{array}{l}\text { The patient presented with a marked decrease in the gray matter to white matter contrast, with predominance of the } \\
\text { sub-temporal, middle, superior and medial areas, as well as additional lateral and medial areas[24]. }\end{array}$ \\
\hline Tanskanen et al., 2010 & $54 / 100$ & $\begin{array}{l}\text { White matter defects were found in extensive networks of prefrontal, temporal, parietal and occipital lobes, subcortical } \\
\text { structures, cerebellum and brainstem, as well as bilateral interhemispheric and interhemispheric tracts[25]. }\end{array}$ \\
\hline Walterfang et al., 2008 & 75 & $\begin{array}{l}\text { Individuals with congenital psychosis are different from those who develop it later. Individuals who develop psychosis later } \\
\text { have a greater volume of white matter in the frontal lobe, particularly in the left hemisphere, and reduced volume in the left } \\
\text { front-occipital tract. Subjects without psychosis showed no reduction in white matter volume but increased white matter } \\
\text { volume in the inferior region of the right parietal lobe [26]. }\end{array}$ \\
\hline Zetzsche et al., 2007 & $50 / 50$ & $\begin{array}{l}\text { The patient had reduced gray matter volume in the right anterior callosal area and the right total ACC. In addition, gray } \\
\text { matter selectivity was reduced in the left ACC subgenus [27]. }\end{array}$ \\
\hline Tamagaki et al., 2005 & $58 / 56$ & $\begin{array}{l}\text { The white matter or gray matter ratio of patients was significantly lower than that of healthy subjects. The relative white } \\
\text { matter volume of the caudate nucleus and nucleus accumbens decreased, while the gray matter volume of putamen } \\
\text { increased. Women had a larger proportion of white matter in both patients and healthy controls[28]. }\end{array}$ \\
\hline Chow et al., 2002 & $14 / 14$ & $\begin{array}{l}\text { Gray matter defects were most evident in the frontal and temporal lobes. Total white matter volume did not differ between } \\
\text { the two groups[29]. }\end{array}$ \\
\hline Sigmundsson et al., 2001 & 1 & $\begin{array}{l}\text { Reduction of grey matter has been found in global, especially left superior temporal gyrus and insular cortex; left medial } \\
\text { temporal lobe (including parahippocampal gyrus and hippocampus); significant loss of gray matter in the anterior } \\
\text { cingulate gyrus and medial frontal gyrus [30]. }\end{array}$ \\
\hline
\end{tabular}

\section{REFERENCES}

[1] Kraepelin, E., \& Barclay, R. M. Dementia praecox and paraphrenia. The Journal of Nervous and Mental Disease, 54(4), 1919, 384.
[2] Bleuler, Eugen (1950). Dementia Praecox or the Group of Schizophrenias. International Universities Press, retrieved from https://philarchive.org/archive/BLEDPO-2v1 
[3] Merritt, K., Luque Laguna, P., Irfan, A., \& David, A. S. Longitudinal Structural MRI Findings in Individuals at Genetic and Clinical High Risk for Psychosis: A Systematic Review. Frontiers in psychiatry, 12, 2021, 49.

[4] Stauffer, E. M., Bethlehem, R. A., Warrier, V., Murray, G. K., Romero-Garcia, R., Seidlitz, J., \& Bullmore, E. T. (2021). Grey and white matter micro-structure is associated with polygenic risk for schizophrenia. medRxiv.

[5] Pijnenborg, G. H. M., Larabi, D. I., Xu, P., HassonOhayon, I., de Vos, A. E., Ćurčić-Blake, B., ... \& Van der Meer, L. Brain areas associated with clinical and cognitive insight in psychotic disorders: A systematic review and metaanalysis. Neuroscience \& Biobehavioral Reviews, 116, 2020, pp. 301-336.

[6] Nazeri, A., Schifani, C., Anderson, J. A., Ameis, S. H., \& Voineskos, A. N. In vivo imaging of gray matter microstructure in major psychiatric disorders: Opportunities for clinical translation. Elsevier, 5(9), 2020, pp.855-864.

[7] Zhang, C., Ni, P., Liu, Y., Tian, Y., Wei, J., Xiang, B., ... \& Li, T. GABAergic abnormalities associated with sensorimotor cortico-striatal community structural deficits in ErbB4 knockout mice and firstepisode treatment-Naïve patients with schizophrenia. Neuroscience bulletin, 36(2), 2020, pp. 97-109.

[8] Drakesmith, M., Parker, G. D., Smith, J., Linden, S. C., Rees, E., Williams, N., ... \& Linden, D. E. Genetic risk for schizophrenia and developmental delay is associated with shape and microstructure of midline white-matter structures. Translational psychiatry, 9(1), 2019, pp.1-13.

[9] Wang, X., Zhao, N., Shi, J., Wu, Y., Liu, J., Xiao, Q., \& Hu, J. (2019). Discussion on the Application of Multi-modal Magnetic Resonance Imaging Fusion in Schizophrenia. Journal of medical systems, 43(5).

[10] Jirsaraie, R. J., Sheffield, J. M., \& Barch, D. M. Neural correlates of global and specific cognitive deficits in schizophrenia. Schizophrenia research, 201, 2018, pp.237-242.

[11] Tamnes, C. K., \& Østby, Y. (2018). Morphometry and development: Changes in brain structure from birth to adult age.

[12] Delvecchio, G., Pigoni, A., Perlini, C., Barillari, M., Ruggeri, M., Altamura, A. C., ... \& Brambilla, P. Sexual dimorphism of the planum temporale in schizophrenia: a MRI study. Australian \& New
Zealand Journal of Psychiatry, 51(10), 2017, pp.1010-1019.

[13] Bopp, M. H., Zöllner, R., Jansen, A., Dietsche, B., Krug, A., \& Kircher, T. T. White matter integrity and symptom dimensions of schizophrenia: a diffusion tensor imaging study. Schizophrenia research, 184, 2017, pp.59-68.

[14] Riddle, K., Cascio, C. J., \& Woodward, N. D. Brain structure in autism: a voxel-based morphometry analysis of the Autism Brain Imaging Database Exchange (ABIDE). Brain imaging and behavior, 11(2), 2017, 541.

[15] Lu, X., Yang, Y., Wu, F., Gao, M., Xu, Y., Zhang, Y., ... \& Wu, K. (2016). Discriminative analysis of schizophrenia using support vector machine and recursive feature elimination on structural MRI images. Medicine, 95(30).

[16] Francx, W., Llera, A., Mennes, M., Zwiers, M. P., Faraone, S. V., Oosterlaan, J., ... \& Beckmann, C. F. Integrated analysis of gray and white matter alterations in attention-deficit/hyperactivity disorder. NeuroImage: Clinical, 11, 2016, pp.357367.

[17] Torres, U. S., Duran, F. L., Schaufelberger, M. S., Crippa, J. A., Louzã, M. R., Sallet, P. C., ... \& Busatto, G. F. Patterns of regional gray matter loss at different stages of schizophrenia: a multisite, cross-sectional VBM study in first-episode and chronic illness. NeuroImage: Clinical, 12, 2016 , pp.1-15.

[18] Hajek, T., Cooke, C., Kopecek, M., Novak, T., Hoschl, C., \& Alda, M. Using structural MRI to identify individuals at genetic risk for bipolar disorders: a 2-cohort, machine learning study. Journal of psychiatry \& neuroscience: JPN, 40(5), 2015, 316.

[19] Nenadic, I., Dietzek, M., Schönfeld, N., Lorenz, C., Gussew, A., Reichenbach, J. R., ... \& Smesny, S. Brain structure in people at ultra-high risk of psychosis, patients with first-episode schizophrenia, and healthy controls: a VBM study. Schizophrenia research, 161(2-3), 2015, pp.169-176.

[20] Jääskeläinen, E., Juola, P., Kurtti, J., Haapea, M., Kyllönen, M., Miettunen, J., ... \& Isohanni, M. Associations between brain morphology and outcome in schizophrenia in a general population sample. European Psychiatry, 29(7), 2014, pp.456462.

[21] Liu, X., Lai, Y., Wang, X., Hao, C., Chen, L., Zhou, Z., ... \& Hong, N. A combined DTI and structural MRI study in medicated-naive chronic 
schizophrenia. Magnetic resonance imaging, 32(1), 2014, pp.1-8.

[22] Thermenos, H. W., Keshavan, M. S., Juelich, R. J., Molokotos, E., Whitfield-Gabrieli, S., Brent, B. K., ... \& Seidman, L. J. A review of neuroimaging studies of young relatives of individuals with schizophrenia: a developmental perspective from schizotaxia to schizophrenia. American Journal of Medical Genetics Part B: Neuropsychiatric Genetics, 162(7), 2013, pp.604-635.

[23] Fusar-Poli, P., Smieskova, R., Kempton, M. J., Ho, B. C., Andreasen, N. C., \& Borgwardt, S. Progressive brain changes in schizophrenia related to antipsychotic treatment? A meta-analysis of longitudinal MRI studies. Neuroscience \& Biobehavioral Reviews, 37(8), 2013, pp.16801691.

[24] Kong, L., Herold, C., Stieltjes, B., Essig, M., Seidl, U., Wolf, R. C., ... \& Thomann, P. A. (2012). Reduced gray to white matter tissue intensity contrast in schizophrenia. PLoS One, 7(5), e37016.

[25] Tanskanen, P., Ridler, K., Murray, G. K., Haapea, M., Veijola, J. M., Jääskeläinen, E., ... \& Isohanni, M. K. Morphometric brain abnormalities in schizophrenia in a population-based sample: relationship to duration of illness. Schizophrenia bulletin, 36(4), 2010, pp.766-777.

[26] Walterfang, M., McGuire, P. K., Yung, A. R., Phillips, L. J., Velakoulis, D., Wood, S. J., ... \& Pantelis, C. White matter volume changes in people who develop psychosis. The British Journal of Psychiatry, 193(3), 2008, pp. 210-215.

[27] Zetzsche, T., Preuss, U., Frodl, T., Watz, D., Schmitt, G., Koutsouleris, N., ... \& Meisenzahl, E. M. In-vivo topography of structural alterations of the anterior cingulate in patients with schizophrenia: new findings and comparison with the literature. Schizophrenia research, 96(1-3), 2007, pp. 34-45.
[28] Tamagaki, C., Sedvall, G. C., Jönsson, E. G., Okugawa, G., Hall, H., Pauli, S., \& Agartz, I. Altered white matter/gray matter proportions in the striatum of patients with schizophrenia: a volumetric MRI study. American Journal of Psychiatry, 162(12), 2005, pp. 2315-2321.

[29] Chow, E. W., Zipursky, R. B., Mikulis, D. J., \& Bassett, A. S. Structural brain abnormalities in patients with schizophrenia and 22q11 deletion syndrome. Biological psychiatry, 51(3), 2002, pp. 208-215.

[30] Sigmundsson, T., Suckling, J., Maier, M., Williams, S. C., Bullmore, E. T., Greenwood, K. E., ... \& Toone, B. K. Structural abnormalities in frontal, temporal, and limbic regions and interconnecting white matter tracts in schizophrenic patients with prominent negative symptoms. American Journal of Psychiatry, 158(2), 2001, pp. 234-243.

[31] Lawrie, S. M., \& Abukmeil, S. S. Brain abnormality in schizophrenia: a systematic and quantitative review of volumetric magnetic resonance imaging studies. The British Journal of Psychiatry, 172(2), 1998, pp. 110-120.

[32 ] Wright, I. C., Ellison, Z. R., Sharma, T., Friston, K. J., Murray, R. M., \& McGuire, P. K. Mapping of grey matter changes in schizophrenia. Schizophrenia research, 35(1), 1999, pp. 1-14.

[33] Kubicki, M., McCarley, R. W., \& Shenton, M. E. Evidence for white matter abnormalities in schizophrenia. Current opinion in psychiatry, 18(2), 2005, 121.

[34] Shenton, M. E., Kikinis, R., Jolesz, F. A., Pollak, S. D., LeMay, M., Wible, C. G., ... \& McCarley, R. W. Abnormalities of the left temporal lobe and thought disorder in schizophrenia: a quantitative magnetic resonance imaging study. New England Journal of Medicine, 327(9), 1992, pp. 604-612. 